\title{
A significant achievement
}

\author{
Ignasi Carrió • Peter Ell
}

Published online: 1 November 2014

(C) Springer-Verlag Berlin Heidelberg 2014

The latest Impact Factor (IF) data for 2013 have been released by the Institute of Scientific Information. Our top two speciality journals occupy places 6 (JNM) and 8 (EJNMMI) in a very long list of journals dedicated to medical imaging as published by Thomson Reuters Web of Science (WOS) 2014. By itself, this represents a remarkable achievement for the Editors of both journals, taking into account the intense competition and the respective "market" sizes of the representative fields of interest - an achievement which for EJNMMI has been consistent, progressive, and maintained for now almost two decades.

Furthermore, if one were to exclude the organdedicated journals from the top of this list, Radiology, JNM and EJNMMI would take pride of place as numbers 1, 2 and 4 among the 120 imaging journals, a magnificent outcome. This also underlines that the number of practitioners in a given medical field does not correlate with academic excellence. From this point of view, nuclear medicine, a small medical speciality, continues to lead proudly in the advancement of medical imaging science as a whole. Table 1 shows the impact factor and other relevant metrics of the nuclear medicine journals in WOS. If we consider European journals only, EJNMMI ranks first in the entire field of radiology, nuclear medicine and medical imaging, with the highest IF ever (Table 2).

I. Carrió $(\bowtie)$

Barcelona, Spain

e-mail: icarrio@santpau.cat

P. Ell

London, UK
It is now inconceivable that modern practice can do without some form of advanced medical imaging. Multimodality imaging is at the forefront of this development, with SPET-CT, PET-CT and now PET-MR. Imaging provides a quantitative regional assessment of the expressed phenotype of the individual patient affected by a pathology, more relevant than ever as one sees the multiplicity of genetic variations encountered even at the level of a single cell. Averaging molecular signals via imaging explain its success as a tool for management.

Table 1 Nuclear medicine journals in WOS for the entire field of radiology, nuclear medicine and medical imaging

ISI WOS 2013

Subject Category: Radiology, Nuclear Medicine and Medical Imaging

\begin{tabular}{llllll}
\hline & $\begin{array}{l}\text { Impact } \\
\text { Factor }\end{array}$ & $\begin{array}{l}\text { Imm. } \\
\text { Index }\end{array}$ & Eigenfactor & $\begin{array}{l}\text { Articles } \\
2013\end{array}$ & $\begin{array}{l}\text { Total } \\
\text { cites }\end{array}$ \\
\hline JNM & 5.563 & 1.055 & 0.04187 & 293 & 21,301 \\
EJNMMI & 5.217 & 1.286 & 0.02555 & 196 & 10,737 \\
Seminars Nucl M & 3.130 & 1.425 & 0.00339 & 40 & 1,773 \\
Mol Im Biology & 2.869 & 0.671 & 0.00619 & 85 & 1,692 \\
Clin Nucl Med & 2.857 & 0.908 & 0.00493 & 119 & 2,899 \\
J Nucl Cardiol & 2.645 & 0.640 & 0.00603 & 89 & 2,544 \\
Nucl Med Biology & 2.408 & 0.752 & 0.00650 & 137 & 3,954 \\
QJNM & 1.724 & 0.459 & 0.00256 & 37 & 952 \\
Nuklearmedizin & 1.671 & 0.341 & 0.00121 & 41 & 519 \\
Ann Nucl Med & 1.507 & 0.274 & 0.00393 & 117 & 1,586 \\
Nucl Med Comm & 1.371 & 0.243 & 0.00459 & 152 & 2,263 \\
Rev Esp Med N & 0.938 & 0.288 & 0.00044 & 59 & 258 \\
Hellenic JNM & 0.925 & 0.212 & 0.00059 & 33 & 1,96 \\
\hline
\end{tabular}


Table 2 European journals in WOS for the entire field of radiology, nuclear medicine and medical imaging
ISI WOS 2013

Subject Category: Radiology, Nuclear Medicine and Medical Imaging (Europe)

\begin{tabular}{llllll}
\hline & Impact Factor & Imm. Index & Eigenfactor & Articles 2013 & Total cites \\
\hline EJNMMI & 5.217 & 1.286 & 0.02555 & 196 & 10,737 \\
Radiother Oncol & 4.857 & 1.092 & 0.03163 & 305 & 12,480 \\
Ultraschall Med & 4.645 & 1.109 & 0.00334 & 55 & 1,332 \\
European Radiol & 4.338 & 0.722 & 0.03271 & 399 & 12,946 \\
Med Image Anal & 3.681 & 0.505 & 0.01017 & 91 & 3,925 \\
NMR Biomed & 3.559 & 0.723 & 0.01344 & 188 & 5,297 \\
Contrast Media Mol I & 3.333 & 0.926 & 0.00377 & 54 & 947 \\
Phys Med Biol & 2.922 & 0.533 & 0.04342 & 546 & 20,225 \\
Strahlenther Onkol & 2.733 & 0.530 & 0.00412 & 117 & 2,381 \\
Neuroradiology & 2.374 & 0.319 & 0.00811 & 166 & 4,806 \\
\hline
\end{tabular}

\section{SUBMISSIONS BY YEAR}

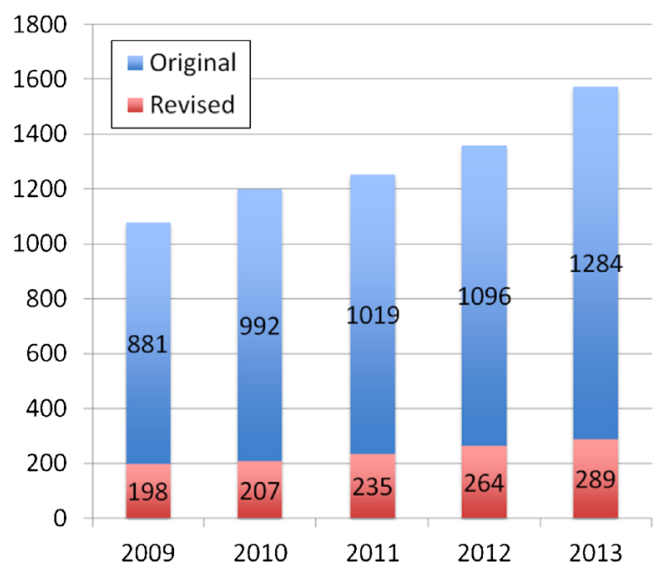

Fig. 1 Number of annual submissions to EJNMMI
Whilst computing, instrumentation developments and design have led the progress in molecular imaging, there remain significant constraints in the availability and also reimbursement of the latest radionuclide probes, which now address major pathologies of our advancing and aging populations. Regulatory issues remain a major obstacle, since they tend to delay the introduction of these tracers to the marketplace and hence raise costs and reduce the appetite for such commercial initiatives. This is of great concern and impedes the progress of molecular imaging as a whole. Our patients deserve more and better from the relevant agencies.

In the meantime, the increasing number of submissions each year (Fig. 1) reflects the vibrancy of the field and the continuing success of EJNMMI. 